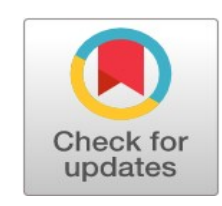

PRIMARY PAPER

\title{
Chromosomal analysis and Nors polymorphism of bagarius suchus (Siluriformes: Sisoridae) by conventional banding and fish techniques
}

\author{
Nuntiya Maneechot ${ }^{1}$, Weerayuth Supiwong ${ }^{2}$, Alongklod Tanomtong ${ }^{3, *}$ \\ ${ }^{1,2,3}$ University Muang KhonKaen, Thailand
}

\author{
Index Terms \\ Bagariussuchus Chromosome \\ Conventional Staining \\ Ag-Nors Banding \\ Fluorescence in Situ \\ Hybridization
}

Received: 15 July 2015

Accepted: 13 January 2016

Published: 22 February 2016

\begin{abstract}
In the present study, conventional staining and NORs banding as well as Fluorescence In Situ Hybridization (FISH) using the 18S rDNA and telomeric (TTAGGG)n probes were applied to stain the chromosomes of crocodile catfish, Bagariussuchus (Siluriformes, Sisoridae) from the Chao Phraya River, Thailand. Kidney cells of six male and six female crocodile catfishes were used as a sample. The mitotic chromosome preparations were done directly from kidney cells. The results showed that the diploid chromosome number of B. suchus was $2 n=56$, the Fundamental Numbers (NF) were 102 in both male and female. The karyotype comprises $17 \mathrm{~m}+17 \mathrm{sm}+12 \mathrm{a}+10 \mathrm{t}$. The Nucleolar Organizer Regions (NORs) were detected by Ag-NORs banding and 18S rDNA probe mapping. The $18 \mathrm{~S}$ rDNA are terminally located on the short arm adjacent to the telomere of the single pair of the 1st chromosome pair whereas NOR-bearing chromosome is only one chromosome of the 1 st chromosome pair (1a $1 \mathrm{~b}$, polymorphic characteristic) at the subtelomeric region of the short arm. Moreover, FISH with telomeric probe showed hybridization signals on each telomere of all chromosomes and interstitial telomeric sites were not detected. There were variations in signals of FISH and their position in the karyotype along with variation in DNA sequences. These markers are useful for future discrimination of population of closely related species and their polymorphism.
\end{abstract}

(C) 2016 The Author(s). Published by TAF Publishing.

\section{INTRODUCTION}

The order Siluriformescomprises 37 recognized families of catfish that are widely distributed and highly diversified in freshwaters [1]. The catfishes of the family Sisoridaeare also the most widely distributed occurring throughout nearly the whole of South and Southeast Asia, from Iran and Turkey in the west [2], [3]. They contain 22 genera

\footnotetext{
* Corresponding author: Alongklod Tanomtong
}

E-mail: tanomtong@hotmail.com and approximately 168 species [4] with new species being discovered frequently [5], [6], [7]. In Thailand, six genera and 18 species were described [8]. Cytogenetic studies in many organisms are quit scarce, in which only conventional technique reported to determine chromosome number and karyotype composition has been performed. Structure, number, and morphology of a NOR may be specific to populations, species and subspecies. NOR is frequently used to compare variations, as well as to identify and explain specifications. Changes in chromosome number and structure can alter the number 
and structure of NOR. Robertsonian translocations may cause losses of NOR. Species which have limited gene exchange due to geographical isolation have elevated karyotype and NOR variety. Therefore, different karyotypes are found even in small and isolated populations of these species. The use of NORs in explaining kinships depends on a large extent on the uniformity of this characteristic and on the degree of variety within a taxon [9]. Very little known concerning its karyological features have been widely accessed by classical methods, and advances in molecular cytogenetics based in FISH experiments have resulted in improved chromosomal mapping of large number of sequences and permitted the study of chromosomal variation.

Accordingly, the goal of this work is finding of NOR polymorphism and chromosomal analysis of the B.suchus from Thailand byusing different staining methods and FISH technique to provide cytotaxonomic information for the understanding of the chromosomal mapping of the Sisoridae family.

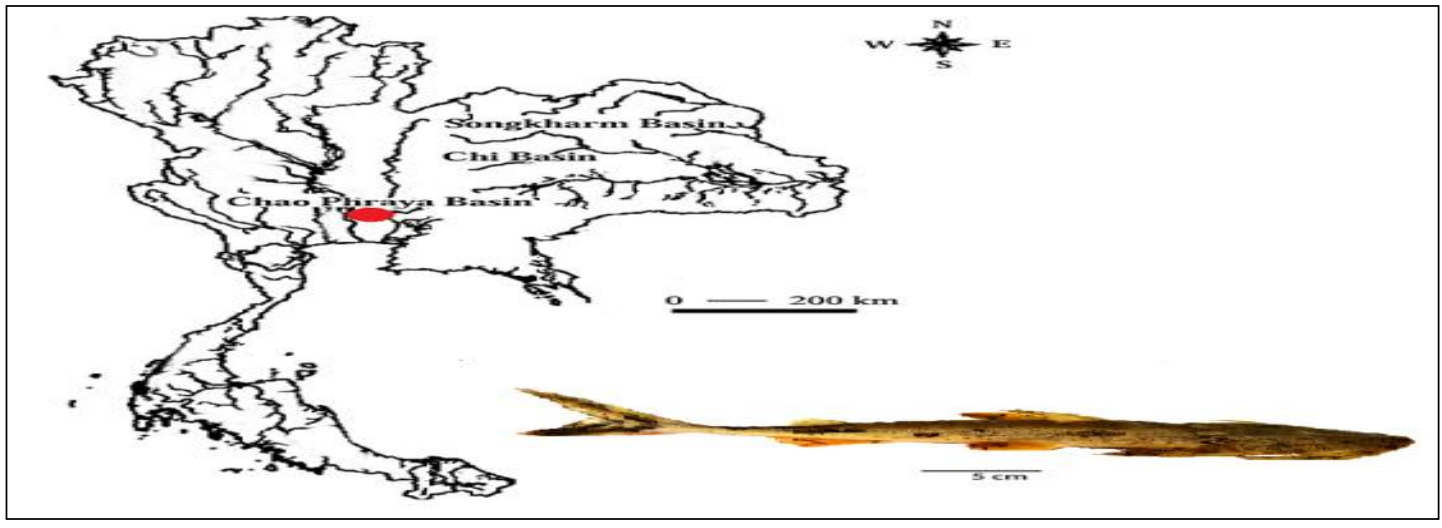

Fig. 1. Collection sites of Bagariussuchus (A) andan individual of the B.suchus(B)

\section{REVIEW OF LITERATURE}

Cytogenetics of the family Sisoridae is scarcely studied. In the genus Bagarius, three species were studied includingB. suchus, B. bagarius and B. yarrelliby [10] using conventional staining method. The results showed that all of them display the same $2 \mathrm{n}$ (56 chromosomes). Their respective NF were 88, 82and 90. The karyotypes comprise $16 m+16 s m+4 s t+20 a, 16 m+10 s m+2 s t+28 a$ and $14 m+20 s m+6 s t+16 a$, respectively. Moreover, some species in other genera in this family (12 reports) have $2 \mathrm{n}$ in the range of 36-62 chromosomes and NF ranges between 66 to 104 Table 2, and molecular cytogenetics techniques have never been applied on these species.In Thailand, there were few molecular cytogenetic studies accomplished by using FISH technique. Up to date, there are few reports on Thai catfish using FISH technique i.e. [11] which demonstrated the nine classes of microsatellite repeats on the chromosomes of hi fin Mystus, Mystusbocourti(family Bagridae). The U2 snRNA, 5S and 18S rDNA were presented in only one chromosomepair but none of them presented in a syntenic position. Microsatellites (CA)15 and (GA)15 showed hybridization signals at subtelomeric regions of all chromosomeswith a stronger accumulation into one specific chromosomal pair. FISH with the telomeric probe revealed hybridization signals on each telomere of all chromosomes and Interstitial Telomeric Sites (ITS) were not detected. In addition, the retrotransposable elements Rex1, 3 and 6 were generally spread throughout the genome.Moreover, the report of [12] showed the distributions in same family of nine species, i.e., Hemibagrusfilamentus; $H$. nemurus; $H$. wyckioides; Mystusatrifasciatus; M. multiradiatus; M. mysticetus; M. bocourti and Pseudomystussiamensis.

Two classes of microsatellites; (CA)15,(GA)15 and one transposable element (TE); Rex1 were mapped by fluorescence in situ hybridization. In all species the microsatellites are abundantly distributed in all chromosomes, usually in the telomeric regions. The retrotransposable element Rex1 is widely distributed over the whole genome including heterochromatin and euchromatin, but with an unexpected accumulation in one chromosome pair in some species. 


\section{RESEARCH METHOD}

\section{A. Biological Material and Chromosome Preparation}

The specimens of both sexes' crocodile catfish,B.suchus(six males and six females) were collected from the Chao Phraya River (Fig. 1), using accidental sampling method by hook. The fishwere transferred to laboratory aquaria and were kept under standard conditions for seven days prior to the experiments. The experiments followed ethical protocols, and anesthesia with clove oil was administered prior to sacrificing the animals to minimize suffering. Mitotic chromosomes were obtained from cell suspensions of the anterior kidney, using the conventional air-drying method [13], [14]. The specimens were deposited in the fish collection of the Cytogenetic Laboratory, Department of Biology, Faculty of Science, KhonKaen University.

\section{B. Giemsa's Staining, Ag-NORs Banding and Karyotype}

The chromosomes were conventionally stained with $20 \%$ Giemsa's solution for 30 minutes [15]. Ag-NOR banding, drops of each $50 \%$ silver nitrate and $2 \%$ gelatin were added on slides, respectively. Then it was sealed with cover glasses and incubated at $60^{\circ} \mathrm{Cfor} 5$ minutes.After that it was soaked indistilled water until the cover glasses were separated [16]. Approximately 30 metaphase spreads were analyzed per specimen to confirm the diploid chromosome number and karyo type structure. Metaphases were photographed under Olympus Bx50 microscope (Olympus Corporation, Ishikawa, Japan). The chromosomes were measured and the Centromere Index (CI), Relative Length (RL), and Centromere Ratio (CR) were calculated. Idiograming is the diagram of chromosomal karyotype of haploid set which includes autosomes and sex-chromosome. The data of average chromosomal length, chromosome type and the position of centromere were used for idiograming construction. To construct idiogram, the 30 metaphase cells from conventional staining were used in karyotyping and then all chromosomes were measured for individual length of both short arm and long arm by vernier calipers.

A graph of an average length of each chromosome pair was plotted using Microsoft Word. Chromosome probes and FISH technique. The $18 \mathrm{~S}$ rDNA probe was direct labeled with Spectrum Orange-dUTP by nick translation according to the manufacture's recommendations (Roche, Mannheim, Germany).

Fluorescence in situ hybridization (FISH) was performed under high stringency conditions on mitotic chromosome spreads [17]. The metaphase chromosome slides were incubated with RNAse $(40 \mu \mathrm{g} / \mathrm{ml})$ for $1.5 \mathrm{~h}$ at $37{ }^{\circ} \mathrm{C}$. After denaturation of chromosomal DNA in $70 \%$ formamide/ $2 \times \mathrm{SSC}$ at $70{ }^{\circ} \mathrm{C}$, spreads were incubated in $2 \times \mathrm{SSC}$ for $4 \mathrm{~min}$ at $70{ }^{\circ} \mathrm{C}$. The hybridization mixture $(2.5$ ng/ $\mu \mathrm{l}$ probes, $2 \mu \mathrm{g} / \mu \mathrm{l}$ salmon sperm DNA, 50\% deionized formamide, $10 \%$ dextran sulphate) was dropped on the slides, and the hybridization was performed overnight at $37{ }^{\circ} \mathrm{C}$ in a moist chamber containing $2 \times \mathrm{SSC}$. The post hybridization wash was carried out with $1 \times \mathrm{SSC}$ for $5 \mathrm{~min}$ at $65{ }^{\circ} \mathrm{C}$. A final wash was performed at room temperature in $4 \times$ SSCT for $5 \mathrm{~min}$. Finally, the slides were counterstained with DAPI and mounted in an antifade solution (Vectashield from Vector laboratories). The detection of the telomeric (TTAGGG)n repeats was made with the FITC-labeled PNA probe (DAKO, Telomere PNA FISH Kit/FITC, Cat. No. K5325) and performed according to manufacturer's recommendations.
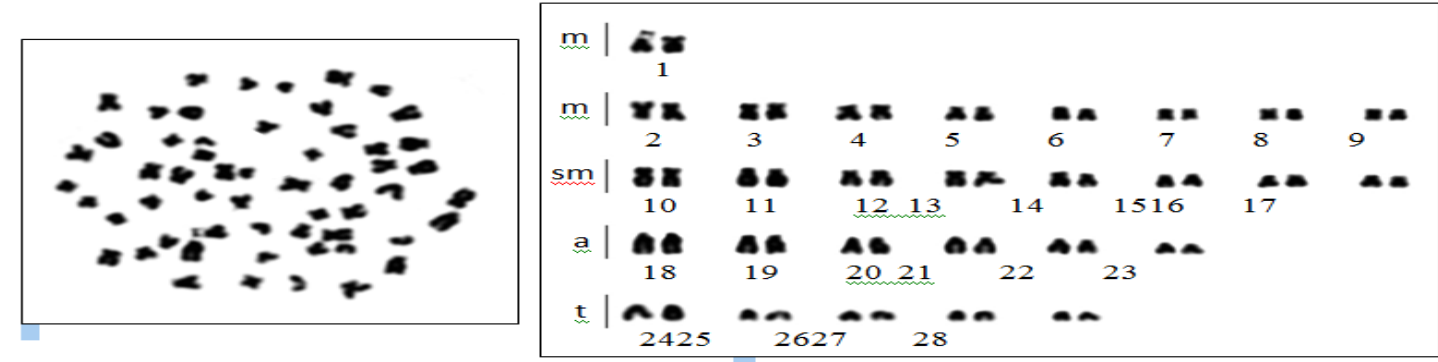

Fig. 2. Metaphase chromosome plate and karyotype of the crocodile 

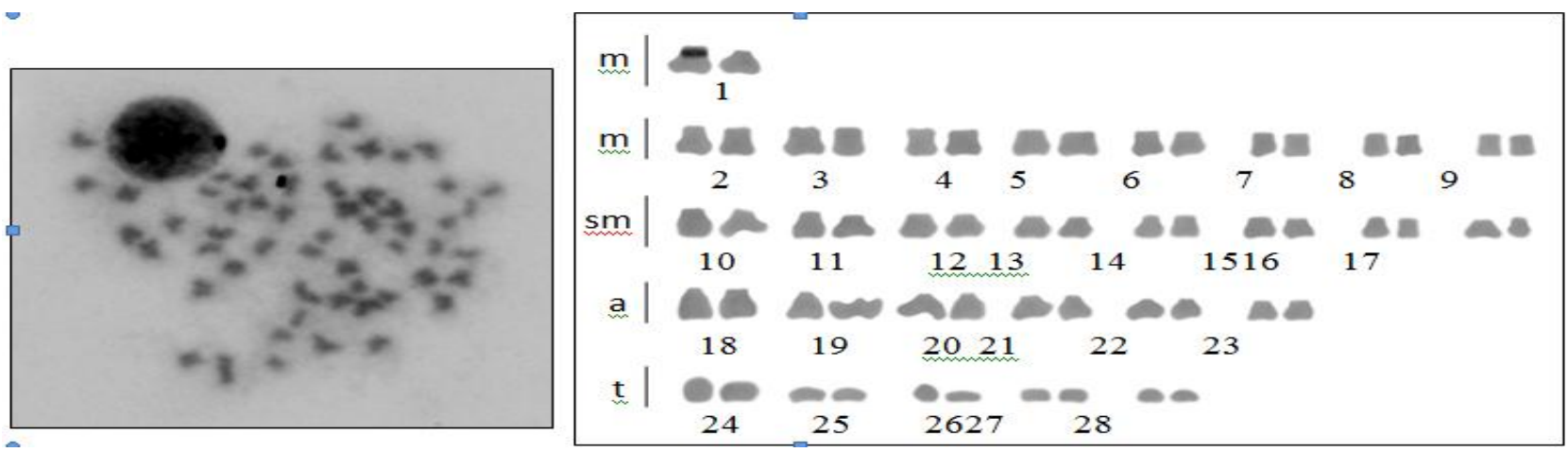

Fig. 3. Metaphase chromosome plate and karyotype of the crocodile catfish

TABLE1

MEAN LENGTH OF SHORT ARM CHROMOSOME

\begin{tabular}{|c|c|c|c|c|c|c|c|}
\hline Chro. & Ls & $\mathrm{Ll}$ & LT & $\mathrm{RL} \pm \mathrm{SD}$ & $\mathrm{CI} \pm \mathrm{SD}$ & Size & Type \\
\hline $1 a^{*}$ & 0.758 & 1.024 & 1.782 & $0.047 \pm 0.004$ & $0.575 \pm 0.012$ & $\mathrm{~L}$ & $\mathrm{M}$ \\
\hline $1 b$ & 0.522 & 0.953 & 1.474 & $0.039 \pm 0.003$ & $0.646 \pm 0.027$ & $\mathrm{~L}$ & $\mathrm{Sm}$ \\
\hline 2 & 0.758 & 0.950 & 1.708 & $0.045 \pm 0.002$ & $0.556 \pm 0.017$ & $\mathrm{~L}$ & M \\
\hline 3 & 0.697 & 0.894 & 1.590 & $0.042 \pm 0.001$ & $0.562 \pm 0.012$ & $\mathrm{~L}$ & M \\
\hline 4 & 0.661 & 0.838 & 1.499 & $0.039 \pm 0.003$ & $0.559 \pm 0.022$ & $\mathrm{~L}$ & M \\
\hline 5 & 0.635 & 0.783 & 1.418 & $0.037 \pm 0.004$ & $0.552 \pm 0.021$ & $\mathrm{~L}$ & M \\
\hline 6 & 0.574 & 0.739 & 1.313 & $0.034 \pm 0.003$ & $0.563 \pm 0.026$ & M & M \\
\hline 7 & 0.564 & 0.705 & 1.269 & $0.033 \pm 0.003$ & $0.556 \pm 0.017$ & M & M \\
\hline 8 & 0.547 & 0.655 & 1.202 & $0.031 \pm 0.003$ & $0.545 \pm 0.016$ & M & M \\
\hline 9 & 0.503 & 0.614 & 1.117 & $0.029 \pm 0.002$ & $0.550 \pm 0.013$ & M & M \\
\hline 10 & 0.551 & 1.012 & 1.563 & $0.041 \pm 0.002$ & $0.648 \pm 0.025$ & $\mathrm{~L}$ & $\mathrm{Sm}$ \\
\hline 11 & 0.496 & 0.954 & 1.450 & $0.038 \pm 0.002$ & $0.658 \pm 0.031$ & $\mathrm{~L}$ & $\mathrm{Sm}$ \\
\hline 12 & 0.512 & 0.883 & 1.395 & $0.037 \pm 0.002$ & $0.633 \pm 0.022$ & $\mathrm{~L}$ & $\mathrm{Sm}$ \\
\hline 13 & 0.486 & 0.856 & 1.342 & $0.035 \pm 0.001$ & $0.638 \pm 0.024$ & $\mathrm{~L}$ & $\mathrm{Sm}$ \\
\hline 14 & 0.472 & 0.826 & 1.298 & $0.034 \pm 0.001$ & $0.636 \pm 0.023$ & M & $\mathrm{Sm}$ \\
\hline 15 & 0.460 & 0.746 & 1.206 & $0.032 \pm 0.001$ & $0.619 \pm 0.016$ & M & $\mathrm{Sm}$ \\
\hline 16 & 0.405 & 0.737 & 1.142 & $0.030 \pm 0.001$ & $0.645 \pm 0.026$ & M & $\mathrm{Sm}$ \\
\hline 17 & 0.378 & 0.714 & 1.092 & $0.029 \pm 0.001$ & $0.654 \pm 0.022$ & M & $\mathrm{Sm}$ \\
\hline 18 & 0.410 & 1.353 & 1.763 & $0.046 \pm 0.001$ & $0.767 \pm 0.026$ & $\mathrm{~L}$ & A \\
\hline 19 & 0.358 & 1.213 & 1.571 & $0.041 \pm 0.002$ & $0.772 \pm 0.044$ & $\mathrm{~L}$ & A \\
\hline 20 & 0.365 & 1.060 & 1.425 & $0.037 \pm 0.002$ & $0.744 \pm 0.034$ & $\mathrm{~L}$ & A \\
\hline 21 & 0.347 & 0.987 & 1.334 & $0.035 \pm 0.002$ & $0.740 \pm 0.025$ & $\mathrm{~L}$ & A \\
\hline 22 & 0.318 & 0.906 & 1.223 & $0.032 \pm 0.002$ & $0.740 \pm 0.026$ & M & A \\
\hline 23 & 0.291 & 0.802 & 1.093 & $0.029 \pm 0.001$ & $0.734 \pm 0.024$ & M & A \\
\hline 24 & 0.000 & 1.323 & 1.323 & $0.035 \pm 0.002$ & $1.000 \pm 0.000$ & $\mathrm{~L}$ & $\mathrm{~T}$ \\
\hline 25 & 0.000 & 0.988 & 0.988 & $0.026 \pm 0.001$ & $1.000 \pm 0.000$ & M & $\mathrm{T}$ \\
\hline 26 & 0.000 & 0.930 & 0.930 & $0.024 \pm 0.001$ & $1.000 \pm 0.000$ & M & $\mathrm{T}$ \\
\hline 27 & 0.000 & 0.874 & 0.874 & $0.023 \pm 0.001$ & $1.000 \pm 0.000$ & $\mathrm{~S}$ & $\mathrm{~T}$ \\
\hline 28 & 0.000 & 0.811 & 0.811 & $0.021 \pm 0.001$ & $1.000 \pm 0.000$ & S & $\mathrm{T}$ \\
\hline
\end{tabular}

Remarks: chro. $=$ chromosome pair,${ }^{*}=$ NOR-bearing chromosome (satellite chromosomes) 


\section{RESULTS}

The diploid number (2n) of B. suchuswas 56chromosomesand the NF was 102 in both sexes (Fig. 2).The karyotpewas composed of $17 m+17 s m+12 a+10 t$. $A$ summary of the results obtained after measuring the chromosomes of 30 complete metaphase plates is presented in Table 1.The analysis of the NORs with the Ag-NOR banding technique sequential to Giemsa's staining, detected that the Ag-positive signal located on the short arm of one chromosome of the 1st chromosome pair (Figs. 3 and 4 A, B).

The 18S rDNA showed hybridization signals at the short arm adjacent to telomere of the 1st chromosome pair (Fig. 5 C). FISH with telomeric sequences (TTAGGG)n were detected the hybridization signals on each telomeric of all chromosomes, and interstitial telomeric sites were not found (Fig. 5 D).

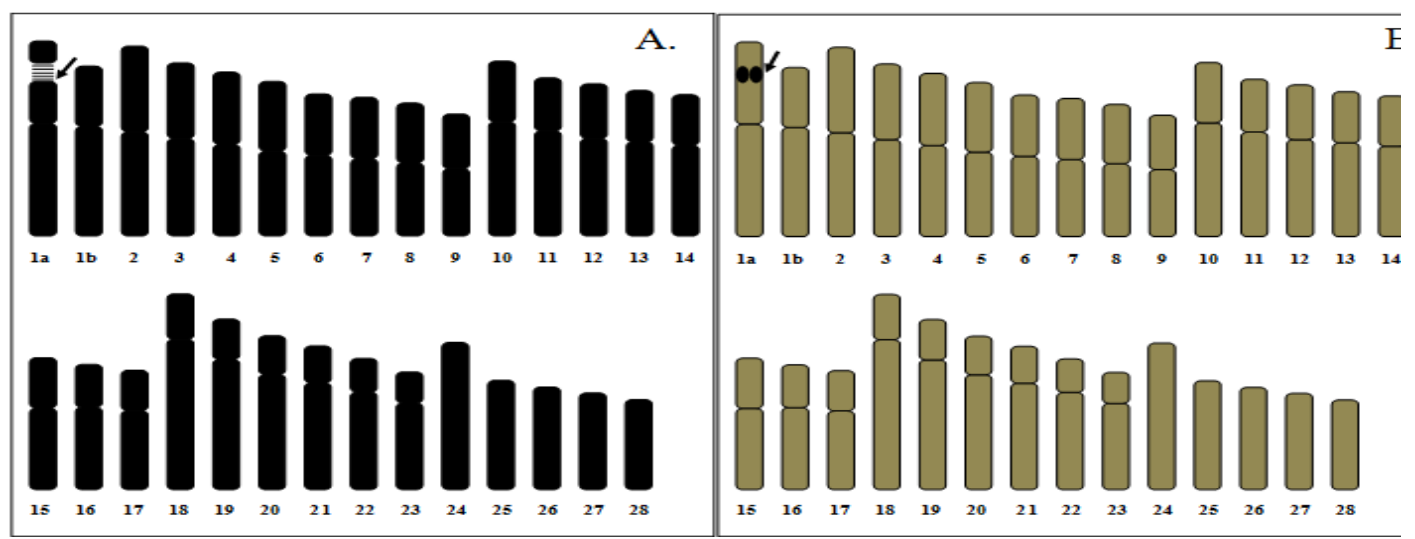

Fig. 4. Idiogram showing lengths and shapes of chromosomes of the crocodile catfish

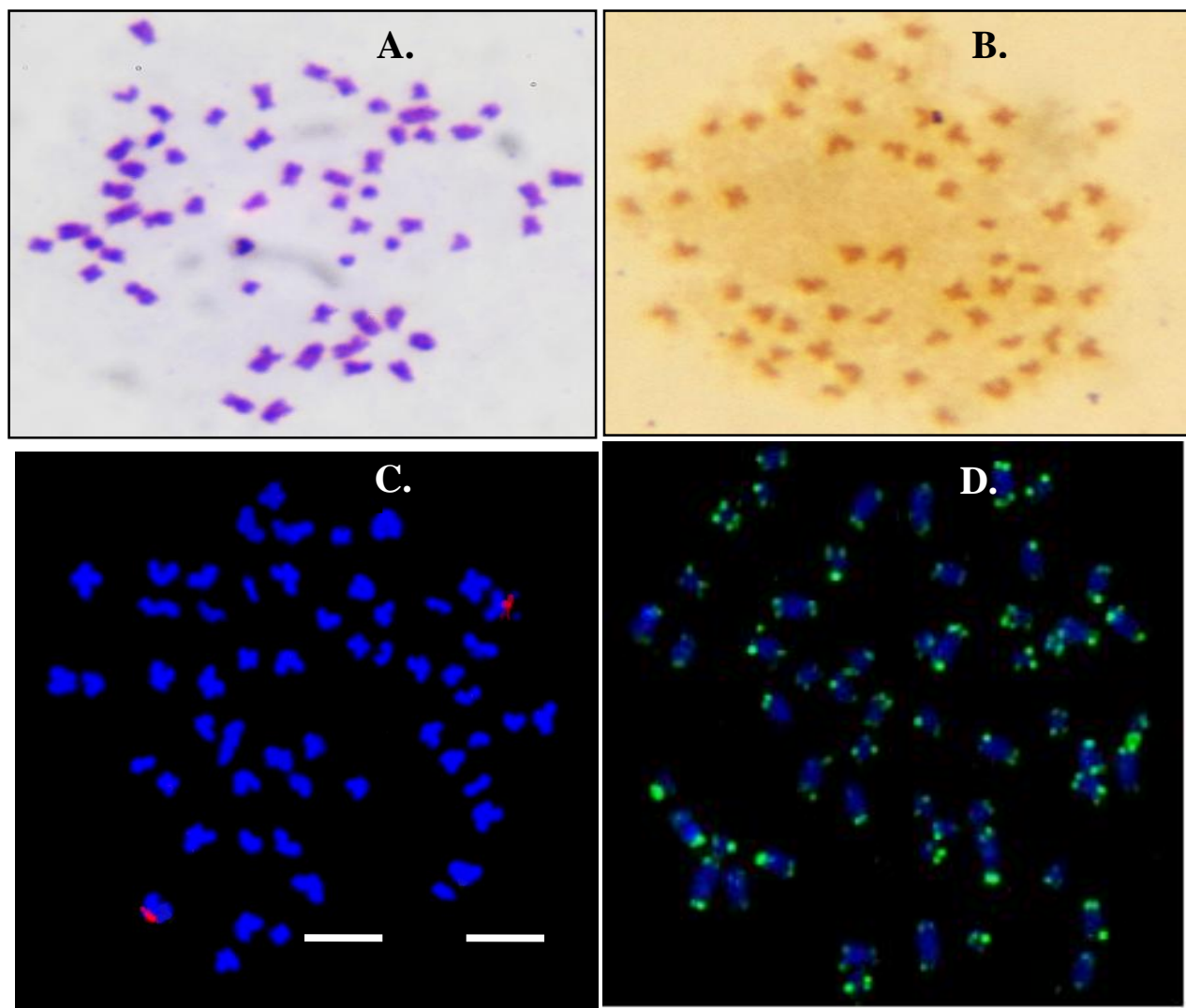

Fig.5. Chromosomal analysis of thecrocodile catfish 
TABLE 2

CYTOGENETIC PUBLICATIONS OF THE FAMILYSISORIDAE

\begin{tabular}{|c|c|c|c|c|c|c|}
\hline Species & $2 n$ & $\mathrm{NF}$ & Karyotype & $\begin{array}{l}\mathrm{Ag}- \\
\text { NORs }\end{array}$ & Locality & Reference \\
\hline \multirow[t]{2}{*}{ Bagariussuchus } & 56 & 88 & $16 m+16 s m+4 s t+20 a$ & - & Thailand & Rangsiruji et al. (2007) \\
\hline & 56 & 102 & $17 m+17 s m+12 a+10 t$ & $1 \mathrm{a}$ & Thailand & The present study \\
\hline B. bagarius & 56 & 82 & $16 m+10 s m+2 s t+28 a$ & - & Thailand & Rangsiruji et al. \\
\hline B. yarrelli & 56 & 90 & $14 m+20 s m+6 s t+16 a$ & - & Thailand & $(2007)$ \\
\hline $\begin{array}{l}\text { Euchioglanisdavi } \\
\text { di }\end{array}$ & 36 & 50 & $8 m+6 s m+22 s t / a$ & - & China & Li et al. (1981) \\
\hline E.kishinouyei & 50 & 70 & $14 m+6 s m+30 s t / a$ & - & China & Li et al. (1981) \\
\hline Gagatacenia & 46 & 66 & $4 m+8 S m+8 s t+26 a$ & - & India & Mishra (1998) \\
\hline $\begin{array}{l}\text { Glyptosternonreti } \\
\text { culatum }\end{array}$ & 42 & - & - & - & India & Rishi et al. (1998) \\
\hline $\begin{array}{l}\text { Glyptothoraxfokie } \\
\text { nsis }\end{array}$ & 52 & 104 & $20 m+18 s m+14 s t$ & - & China & Yu et al. (1989) \\
\hline G. telchitta & 56 & 102 & $18 m+26 s m+2 s t+10 a$ & - & India & Khuda-Bukhsh et al. (1986) \\
\hline \multirow{2}{*}{$\begin{array}{l}\text { G. } \\
\text { glyptothoraxtrilin } \\
\text { eatus }\end{array}$} & 52 & - & $18 m+24 s m+10 a$ & - & India & Khuda-Bukhshet al. (1995) \\
\hline & 62 & 90 & $16 m+12 s m+2 s t+32 a$ & & Thailand & Rangsiruji et al. (2007) \\
\hline \multirow{2}{*}{$\begin{array}{l}\text { Gogangraviridesc } \\
\text { ens }\end{array}$} & 42 & - & $14 m+20 s m+8 a$ & - & India & Khuda-Bukhsh et al. (1995) \\
\hline & 48 & 86 & $12 m+22 s m+4 s t+10 a$ & - & India & Sharma \&Tripathi (1981) \\
\hline \multirow{2}{*}{$\begin{array}{l}\text { Pseudecheneissul } \\
\text { cata }\end{array}$} & 52 & - & $8 m+14 s m+30 s t / a$ & - & India & Rishi et al. (1998) \\
\hline & 48 & 86 & $12 m+22 s m+4 s t+10 a$ & - & India & Sharma\&Tripathi (1981) \\
\hline
\end{tabular}

\section{DISCUSSION}

The B.suchushad $2 \mathrm{n}=56$ which is in accordance with the previous study conducted by [11]. Such $2 \mathrm{n}$ is also same as the other species of the genus Bagarius (Table 2). However, the NF was 102 and karyotype composed of $17 m+17 s m+12 a / s t+10 t / a$ chromosomes, which differ from the previous study of [10] that reported the karyotype of B. suchus consisting of $16 m+16 s m+4 a / s t+20 t / a$ chromosomes and $N F=88$.The hypothetical $2 \mathrm{n}$ for Siluriformes, as described in studies of different species of this order, was proposed to be $2 n=56$, with a karyotype composed mainly by $\mathrm{m}$-sm chromosomes [18], [19], [20] accordance with the present study were $17 m+17 s m+12 a+10 t$. This fact suggests that some pericentric inversions have occurred in the karyotype differentiation of this species. In fact, the occurrence of chromosomal rearrangements has been considered a relatively common evolutionary mechanism inside the
Sisoridae family [12].The analysis of the NORs with the AgNOR banding sequential to Giemsa's staining, detected the Ag-positive signals at the short arm of only one chromosome of the 1st metacentric chromosomepair.This is the first study of NOR bearing chromosome in the family Sisoridae. The NORs are effective cytotaxonomic markers in family Sisoridae and allowed us to distinguish most of the analyzed species, in which the ribosomal sites were similarly located on the same chromosomal pair (chromosome pair 1).The present study showed that a polymorphism of chromosome is only one chromosome of the 1st chromosome pair (1a 1b). This is in agreement with several previous reports on the finding in Moenkhausiasanctae filomenae [21], Aphaniusfasciatus [22], Leporinusfriderici [21], Salmo trutta [23], Salvelinus alpines [24] Chondrostomalusitanicum [25], Hopliasmalabaricus [26], Oedalechiluslabeo [27], Astyanax scabripinnis [28], A. altiparanae Bryconamericusaff. exodon [29], Apareiodonaffinis Aphaniusfasciatus [22], 
Prochiloduslineatus B. aff. iheringii [30], and Puntioplitesproctozysron [31]. NORs can be the perfect markers to display wide chromosomal polymorphism within and between species in many groups of fishes. This variety may affect NOR number, its localization on the chromosome, size, and active numbers in each genome. The previous NORs studies showed variations between species, within species, and even between individuals [21], [23].

Karyotype diversification processes in species are subject to multiple factors, whether intrinsic (genomic or chromosomal particularities) or extrinsic (historic contingencies). Among these, restricted gene flow between populations is an important factor for fixation of karyotype changes. For example, after the occurrence of an inversion, it can be lost in the polymorphic state or, under the proper conditions, spread in the population until it is fixed. Inversions maintain areas of imbalance between alleles in loci within or influenced by these rearrangements, leading to an adaptive condition, primarily along environmental gradients. This could occur, particularly in relation to possible historical expansion and adaptation to new environments [32].

Ribosomal RNA genes are among the most mapped sequences in fish chromosomes. Accordingly, they can be excellent genetic markers for the comparative genomic studies, evolutionary studies as well as the genetic identification of fish species [27]. In higher eukaryotes, the moderately repetitive ribosomal RNA genes (rDNAs) are arranged in two different families: the nucleolus forming major (45S) and the non-nucleolus forming minor (5S) rDNAs. The major family is composed of the regions coding for 18S, 5.8S and 28S rRNA genes separated by internal transcribed spacers (ITS 1 and ITS 2) and surrounded by Non Transcribed Spacer (NTS) sequences [33], [34]. The nucleolar organizer regions (NORs) contain 45S rDNA gene cluster, which has also been studied by means of AgNO3 and CMA3 staining. The minor family is composed of a highly conserved $120 \mathrm{bp}$ long coding sequences separated by variable NT). In several fish species, chromosome location of the two rDNA families are usually different [35], [36], [24], [37], [28].

The FISH helped simultaneous chromosomal localization of the 18S rDNA on the chromosomes of B. suchus and is being reported for the first time. In the present study, NOR signal was observed only one chromosome of the 1st chromosome pair (1a 1b) using silver nitrate staining that stains only transcriptionally active regions, whereas the FISH is able to detect $18 \mathrm{~S}$
rDNA on both homologous chromosomes pair. Thus, the molecular karyotyping using FISH technique helps precise characterization of this species. Furthermore, the $18 \mathrm{~S}$ rDNA probe has been considered as an important marker to evidence the karyotypic differentiation, which is not detected by conventional tools, in species considered karyotypically conserved and uniform [38]. The heteromorphism of signal intensity observed between homologous chromosomes may be caused by a variety of mechanisms, namely unequal crossing over, transposition, tandem amplification and other rearrangements involving homologous segments causing structural modifications in the NORs [39], [40].

Telomeric (TTAGGG)n sequences are present in the telomeres of vertebrate chromosomes, and the study of these sequences provides insight into the chromosomal rearrangements that have occurred during karyotype evolution of distinct organisms,[41]. FISH with the telomeric (TTAGGG)nprobe revealed hybridization signals on each telomere of all chromosomes and internal transcribed spacers were not observed, which indicates that Robertsonian fusions or chromosomal translocations might be not involved in the karyotypic evolution ofB. suchus.

In this respect, cytogenetic techniques have been used to characterize populations, species, genera and families, and many of them have proved to be efficient marker in identifying intra and inter-specific banding/staining techniques. They have facilitated accurate chromosome identification and permitted a better understanding of cytogenetics. These finding have revealed the mechanisms involved in the evolutionary processes. Recently, the studies on chromosome structure and evolution were challenged with the introduction of new molecular cytogenetic techniques that enabled taxonomic identification of species with the use of genes or specific genomic segments. This will eventually help in fisheries development through better management of genetic resources [42].

\section{CONCLUSION}

The conclusion of the present study supported the conserved of the diploid chromosome numbers was 56 in Bagarius species. However, variation in karyotype has been reported in this family, which is summarized in table 2. It is evident from the frequency distribution that $2 \mathrm{n}=56$ is by far the most common diploid chromosome number in catfishes. The variation in karyotypes between 
species may be due to prevalence of non-Robertson a rearrangements.There were variations in signals of FISH and their position in the karyotype along with variation in DNA sequences. These markers may be future useful for discrimination of population of closely related species and their polymorphism. Nevertheless, two probes were used in the present study; even so, other probes such as microsatellites should be used in the further comparative studies. In the same way, others in the family Sisoridae should be studied additionally to explain properly of the chromosomal evolution in this family.

\section{ACKNOWLEDGEMENT}

This work was supported by Toxic Substances in Livestock and Aquatic Animals Research, Department of Biology, Faculty of Science, KhonKaen University. I would like to thanks the Royal Thai Government scholarship National Science and Technology Development Agency (NSTDA) for financial support.

\section{REFERENCES}

[1] J. P. Sullivan, J. G. Lundberg and M. Hardman, "A phylogenetic analysis of the major groups of catfishes (Teleostei: Siluriformes) using rag1 and rag2 nuclear gene sequences," Molecular Phylogenetics and Evolution., vol. 41, no. 3, pp. 636-662, 2006. DOI: 10.1016/j.ympev.2006.05.044

[2] B. W. Coad, "Glyptothorax silviae, a new species of sisorid catfish from southwestern Iran," Japanese Journal of Ichthyology (Japan), 1981.

[3] B. W. Coad and G. B. Delmastro, "Notes on a sisorid catfish from the Black Sea drainage of Turkey: Notes sur un Sisoridae du bassin versant (de la Mer Noire en Turquie)," 1985.

[4] C. J. Ferraris, "Checklist of Catfishes, Recent And Fossil (Osteichthyes: Siluriformes), and Catalogue of Siluriform Primary Types," Auckland, New Zealand: Magnolia Press, pp. 1-628, 2007.

[5] M. A. Kottelat, "New species of Erethistes Müller \& Troschel from Thailand and Burma (Osteichthyes: Siluriformes: Sisoridae)," Hydrobiologia, vol. 107, no. 1, pp. 71-74, 1983. DOI: 10.1007/BF00126706

[6] T. P. Mo and X. L. Chu, "A revision of the sisorid catfish genus Glyptothorax from China," Zoological Research, vol. 7, no. 4, pp. 339-350, 1986.

[7] R. H. Ding, T. Y. Fu and M. R. Ye, "Two new species of the genus Pareuchiloglanis from China (Siluriformes: Sisoridae)," Acta Zootaxonomica Sinica, vol. 16, no. 3, pp. 369-374, 1991.

[8] C. Vidthayanon, J. Kanasuta and J. Nabhitabhata, "Diversity of Freshwater Fishes in Thailand," Integrated Promotion Technology Company ltd, Bangkok: Thiland, 1997.

[9] E. Yüksel and M. Gaffaroglu, "The analysis of nucleolar organizer regions in Chalcalburnus mossulensis (Pisces: Cyprinidae)," Journal of Fisheries Sciences, vol. 2, no. 4, pp. 587-591, 2008. DOI: $10.3153 /$ jfscom. 2008021

[10] A. Rangsiruji, W. Magtoon and T. Donsakul, "Karyotypes of four sisorid catfishes: Bagarius bagarius, B. yarrelli, B. suchus and Glyptothorax trilineatus from Thailand." In Proc. Kasetsart University Annual Conference, Bangkok Thailand, 2007, pp. 45.

[11] W. Supiwong, T. Liehr, M. B. Cioffi, A. Chaveerach, N. Kosyakova, K. Pinthong and A. Tanomtong, "Karyotype and cytogenetic mapping of 9 classes of repetitive DNAs in the genome of the naked catfish Mystusbocourti (Siluriformes, Bagridae)" Molecular Cytogenetics, vol. 6, no. 51, 2013. DOI:

10.1186/1755-8166651

[12] W. Supiwong, T. Liehr, M. B. Cioffi, A. Chaveerach, N. Kosyakova, K. Pinthong and A. Tanomtong, "Chromosomal evolution in naked catfishes (Bagridae, Siluriformes): A comparative chromosome mapping study," Zoologischer AnzeigerA Journal of Comparative Zoology, vol. 253, no. 4, pp. 316-320. 2014. DOI: http://dx.doi.org/10.1016/j.jcz.2014.02.004

[13] T. R. Chen and A. W. Ebeling, "Karyological evidence of female heterogamety in the mosquitofish, Gambusia affinis," Copeia, pp. 70-75, 1968.

[14] D. E. Salt, M. Blaylock, N. P. Kumar, V. Dushenkov, B. D. Ensley, I. Chet and I. Raskin, "Phytoremediation: A novel strategy for the removal of toxic metals from the environment using plants," Nature biotechnology, vol. 13, no. 5, pp. 468-474, 1995.

[15] D. E. Rooney, Human Cytogenetics: Constitutional Analysis; A Practical Approach. Cambridge, MA: Oxford University Press, 2001.

[16] W. T. Howell and D. A. Black, "Controlled silverstaining of nucleolus organizer regions with a protective colloidal developer: A 1-step method," Experientia, vol. 36, no. 8, pp. 1014-1015, 1980. DOI: 10.1007/BF01953855

[17] C. J. Der, T. Finkel and G. M. Cooper, "Biological and biochemical properties of human ras $\mathrm{H}$ genes mutated at codon 61," Cell, vol. 44, no. 1, pp. 167-176, 1986. 
[18] P. Rab, "Karyotype of European catfish Silurus glanis (Siluridae, Pisces), with remarks on cytogenetics of siluroid fishes," Folia Zoologica. 1981.

[19] W. H. LeGrande," Chromosomal evolution in North American catfishes (Siluriformes: Ictaluridae) with particular emphasis on the madtoms noturus," Copeia, vol. 1981, no. 1, pp. 33-52, 1981. DOI: $10.2307 / 1444039$

[20] N. Maneechot, C. F. Yano, L. A. C. Bertollo, N. Getlekha, W. F. Molina, S. Ditcharoen and M. de Bello Cioffi, "Genomic organization of repetitive DNAs highlights chromosomal evolution in the genus Clarias (Clariidae, Siluriformes)," Molecular Cytogenetics, vol. 9, no. 1, pp. 1, 2016. DOI:

10.1186/s13039-016-02152

[21] P. M. Galetti Jr, F. Foresti, L. A. C. Bertollo and F. O. Moreira "Characterization of eight species of Anostomidae (Cypriniformes) fish on the basis of the nucleolar organizing region," Caryologia, vol. 37, no.

4, pp. 401-406, 1984. DOI:

10.1080/00087114.1984.10797718

[22] M. S. Colomba, E. Monteresino, R. Vitturi and M. Zunino, "Charakterization of Mitotic Chromosomes Of The Scarab Beetles Glyphoderus steriquilinus (Westwood) und Bubas bison (L. )(Coleoptera: Scarabaeidae) Using Conventional And Banding Technics)," Biologisches Zentralblatt, vol. 115, no. 1, pp. 58-70, 1996.

[23] J. Castro, A. Viñas, L. Sánchez and P. Martínez, "Characterization of an atypical NOR site polymorphism in brown trout (Salmo trutta) with Ag-and CMA3-staining, and fluorescent in situ hybridization," Cytogenetic and Genome Research, vol. 75, no. 4, pp. 234-239. 1996. DOI: 10.1159/000134491

[24] S. L. Sajdak, K. M. Reed and R. B. Phillips, "Intraindividual and interspecies variation in the $5 \mathrm{~S}$ rDNA of coregonid fish," Journal of Molecular Evolution, vol. 46, no. 6, pp. 680-688, 1998. DOI: 10.1007/PL00006348

[25] E. Rodrigues and M. J. Collares-Pereira, "NOR polymorphism in the Iberian species Chondrostoma lusitanicum (Pisces: Cyprinidae)," Genetica, vol. 98, no. 1, pp. 59-63, 1996.

[26] D. A. de Marco Ferro, D. M. Néo, O. Moreira-Filho and L. A. C. Bertollo, "Nucleolar organizing regions, $18 \mathrm{~S}$ and 5S rDNA in Astyanax scabripinnis (Pisces, Characidae): populations distribution and functional diversity," Genetica, vol. 110, no. 1, pp. 55-62. 2000. DOI: http://dx.doi.org/10.1023/A:1017963217795
[27] F. Fontana, M. Lanfredi, L. Congiu, M. Leis, M. Chicca and R. Rossi, "Chromosomal mapping of $18 \mathrm{~S} 28 \mathrm{~S}$ and $5 \mathrm{~S}$ rRNA genes by two-colour fluorescent in situ hybridization in six sturgeon species," Genome, vol. 46, no. 3, pp. 473-477. 2003. DOI: 10.1139/g03007

[28] D. A de Marco Ferro, O. Moreira-Filho and L. A. C. Bertollo, "B chromosome polymorphism in the fish, Astyanax scabripinnis," Genetica, vol. 119, no. 2, pp. 147-153, 2003.

[29] T. R. Paintner-Marques, L. Giuliano-Caetano and A. L. Dias, "Karyotypic Diversity in a Bryconamericus aff. exodon Population (Characidae, Tetragonopterinae)," Cytologia, vol. 67, no. 4, pp. 397-402, 2002.

[30] T. G. Capistano, A. L. D. B. P. Castro and H. F. JulioJunior, "Chromosome divergence and NOR polymorphism in Bryconamericus aff. iheringii (Teleostei, Characidae) in the hydrographic systems of the Paranapanema and Ivaí Rivers, Paraná, Brazil," Genetics and Molecular Biology, vol. 31, no. 1, pp. 203-207, 2008.

[31] W. Supiwong, A. Tanomtong, P. Supanuam, S. Jantarat, S. Khakhong and L. O. Sanoamuang, "A discovery of nucleolar organizer regions (NORs) polymorphism and karyological analysis of Smith's barb, Puntioplites proctozysron (Cypriniformes, Cyprinidae)," Cytologia, vol. 77, no. 1, pp. 35-42, 2012. DOI:

10.1508/cytologia.77.35

[32] A. A. Hoffmann and L. H. Rieseberg, "Revisiting the impact of inversions in evolution: From population genetic markers to drivers of adaptive shifts and speciation," Annual Review of Ecology Evolution and Systematic, vol. 39, no. 21, 2008. DOI: 10.1146/annurev.ecolsys.39.110707.173532

[33] E. O. Long and I. B. Dawid, "Repeated genes in eukaryotes," Annual Review of Biochemistry, vol. 49, no. 1, pp. 727-764, 1980. DOI: 10.1146/annurev.bi.49.070180.003455

[34] A. M. Pendás, P. Móran, J. P. Freije and E. Garcia Vásquez, "Chromosomal location and nucleotide sequence of two tandem repeats of the Atlantic salmon 5S rDNA," Cytogenetics and Cell Genetics, vol. 67, pp. 31-36, 1994. DOI: $10.1159 / 000133792$

[35] J. L. Martinez, P. Morán, E. Garcia-Vazquez and A. M. Pendás, "Chromosomal localization of the major and 5S rRNA genes in the European eel (Anguilla anguilla)," Cytogenetic and Genome Research, vol.

73, no. 1-2, pp. 149-152, 1996. DOI: 
$\underline{10.1159 / 000134328}$

[36] M. C. Yoshida, "Chromosomal localization and heterochromatin association of ribosomal RNA gene loci and silver-stained nucleolar organizer regions in salmonid fishes Atushi Fujiwara, Syuiti Abe, Etsuro Yamaha, Fumio Yamazaki," Chromosome Research, vol. 6, pp. 463-471, 1998. DOI: 10.1023/A:1009200428369

[37] C. Martins, A. P. Wasko, C. Oliveira and J. M. Wright, "Nucleotide sequence of 5S rDNA and localization of the ribosomal RNA genes to metaphase chromosomes of the Tilapiine cichlid fish, Oreochromis niloticus," Hereditas, vol. 133, no. 1, pp. 39-46, 2000. DOI: 10.1073/pnas.86.18.7049

[38] M. C. Almeida, L. G. Goll, R. F. Artoni, V. Nogaroto, R. R. Matiello and M. R. Vicari, "Physical mapping of 18S rDNA cistron in species of the Omophoita genus (Coleoptera, Alticinae) using fluorescent in situ hybridization," Micron, vol. 41, no. 7, pp. 729-734, 2010. Doi: 10.1016/j.micron.2010.06.008

[39] M. R. Vicari, R. Ferreira Artoni, O. Moreira-Filho and L. A. C. Bertollo, "Basic and molecular cytogenetics in freshwater Cichlidae (Osteichthyes, Perciformes):
Karyotypic conservationism and divergence," Caryologia, vol. 59, no. 3, pp. 260-266, 2006. DOI: 10.1080/00087114.2006.10797924

[40] T. S. Sczepanski, R. B. Noleto, M. M. Cestari and R. F. Artoni, "A comparative study of two marine catfish (Siluriformes, Ariidae): Cytogenetic tools for determining cytotaxonomy and karyotype evolution," Micron, vol. 41. No. 3, pp. 193-197, 2010. DOI: $10.1016 / j . m i c r o n .2009 .11 .004$

[41] J. Meyne, R. L. Ratliff and R. K. MoYzIs, "Conservation of the human telomere sequence (TTAGGG) n among vertebrates," In Proc. of the National Academy of Sciences, vol. 86, no. 18, 1989, pp. 7049-7053.

[42] R. Kumar, B. Kushwaha and N. S. Nagpure, "Characterization and physical mapping of $18 \mathrm{~S}$ and $5 \mathrm{~S}$ ribosomal genes in Indian major carps (Pisces, Cyprinidae)," Micron, vol. 49, pp. 40-45, 2013. DOI: 10.1016/j.micron.2013.03.001

[43] A. R. Khuda-Bukhsh and A. Khuda-Bukhsh, "Diploid numbers and chromosome formulae of some 29 species of Indian teleosts (Pisces)," Chromosome Information Service, vol. 58, pp. 38-39, 1995.

— This article does not have any appendix. - 